\title{
Trendy blends: A new addition to English lexicon
}

\author{
Massrura Mostafa \\ Department of English Language and Literature, Northern University Bangladesh, Bangladesh
}

Email address:

massrura12@yahoo.com

\section{To cite this article:}

Massrura Mostafa. Trendy Blends: A New Addition to English Lexicon. International Journal of Language and Linguistics. Vol. 1, No. 4, 2013, pp. 147-154. doi: 10.11648/j.ij11.20130104.18

\begin{abstract}
New words are created in our society everyday due to several reasons. It is important to understand the processes by which new words are formed. The processes traditionally identified may not adequately account for the formation of some neologisms; they [may] need updating. Among the traditionally-identified word-formation processes, blending is the most common. Some of the trendy blends are mostly derived from commercial trade names or advertising, science and technology, or simply a desire to be clever, witty, or facetious. In this paper, I will be discussing a number of trendy new blends, focusing on those which have violated the traditional rules of blend formation. For example, netizen, a variant of citizen, is the result of the amalgamation of Internet and citizen. Here, the word net, a [front-] clipping of Internet, and the last part of citizen, (it)izen, are combined. The use of such blending has become so frequent that these new processes should be recognized and accepted as new rules. Generally, the established rule of blending is that the first part of one word is added to the last part of another word, and the new word formed conveys the combined meaning of the two words. However, this is patently no longer the only way to blend words into a neologism. Therefore, if the new rules were added to the old one, the study of neologisms would become a little easier for learners.
\end{abstract}

Keywords: Blends, Neologisms and Morphology

\section{Introduction}

The study of neologisms and neosemantics is a growing need of our time. The English language is changing rapidly, and we need to know how and why. There is no single day when new words are not created in our society, because cultures, norms and languages are not static at all. Old or obsolete give way to new words. New technologies, discoveries, and conceptions lead to the need to create new words. Our tendency to shorten expressions is also responsible for creating new words. It is important to understand the processes by which new words are formed. The processes traditionally identified may not adequately account for the formation of some neologisms; they [may] need updating. Among the traditionally-identified wordformation processes, blending is the most common. Usually, in word formation, we combine roots or affixes along their edges: one morpheme comes to an end before the next one starts. For example, we form derivation out of the sequence of morphemes de+riv+at(e)+ion. One morpheme follows the next, and each one has identifiable boundaries. The morphemes do not overlap. However, in blending, part of one word is stitched onto another word, without any regard for where one morpheme ends and another begins, as in mockumentary (mock and documentary). Algeo's (1977: 48) definition of blends is: "a combination of two or more forms, at least one of which has been shortened in the process of combination". Bauer's (1983: 235) definition is that 'blends normally take the first part of one word and the last part of another". Kemmer (2003: 75) states that "blends combine parts of lexical source words, rather than whole source words; this distinguishes them from compounds. Morphological structure is not particularly relevant to blends. [ . . . ] Phonological properties are highly relevant to blending; phonological similarity of the blend with part or whole source word increases the likelihood or felicity [. . . of the blend". Cannon (1986: 739) notes that "a blend should not differ very much in form and meaning from its sources $[\ldots]$ the major parts of the source words should be preserved". Gries (2004: 661) explains that as "blends exhibit many structural characteristics, their structure is governed by a desire to guarantee the recognizability of both source words".

These days, resources such as Word Spy, The Oxford Dictionary of New Words, The New Scrabble Dictionary, and The Urban Dictionary are well known repositories of 
new words. These sources enable us to verify the existence, meaning, and usage of new words. However, not all new words created by blending last long because some are created for/by a particular group of society and then used only [somewhat esoterically] by that particular demographic. If the words are not spread by being widely used, they may disappear [or remain an arcane argot]. However, if a word is coined that aptly meets a [linguistic] need, it gains currency, credibility, and stability and becomes accepted into a general term dictionary. Examples of such well-established blended neologisms are brunch (breakfast and lunch) and smog (smoke and fog).

The blend is a type of word formation which has become particularly popular in English in this new century, now accounting for a significant proportion of new words. These new and/or trendy blends are mostly derived from commercial trade names or advertising, science and technology, or simply a desire to be clever, witty, or facetious. In this paper, the researcher will be discussing such trendy new blends, focusing on those which have violated the traditional rules of blend formation. According to Algeo [quoted above], the traditional process of forming a blend is that the beginning of one word is added to the end of the other. For example, [the aforementioned] brunch is a blend of breakfast and lunch. However, in this paper, I aim to show that the trendy blends are also being formed by a few more methods than this one alone. Blends occur in advertisement, journalism, and media functioning to gain our attention. This marginalized area is increasingly getting popularity and they tell much about English language usage. But they create a problem for the hearer to segment them. Hence, in this article they segmented and a detailed description is provided for better understanding them.

\section{Methodology}

In undertaking this research, blends were collected from the webpage of Word Spy, written by Paul McFedries (2004). These words are not yet included in general term dictionaries, but these creations nevertheless certainly call for a linguistic study to enrich our understanding of modern/contemporary morphology.

The Internet was the main resource and tool for this research, specifically websites such as and Wiktionary. In addition, web dictionaries such as the Urban Dictionary and Longman English Dictionary Online were of great help. Thousands of trendy words are found on the Internet from various contemporary articles, magazines, newspapers, and speeches. Among them words which have been created violating the existing rule of blending are selected. The researcher have analyzed their morphological processes, discussed their formation and made a chart to show their roots, additions, and usage. These words have all been checked in an online corpus, Web Corp, to verify the tendencies of their usage and acceptability.

\section{Description of the Trendy Words Coined By Blending}

\subsection{Framily (n): (Family + Friend)}

The word framily is the blend of the words family and friend. Here, the letter ' $r$ ' of friend is inserted within the word family to create a new word: 'framily'. Only the ' $r$ ' is taken from the word 'friend' and inscribed in 'family' to put emphasis on the word 'family'. Framily means 'a person's closest friends, particularly those who feel like part of the family" (McFedries: 2009). Here the status of a friend is heightened by making him/her equivalent to a family member. All the letters of the word 'family' are kept intact. It is a very unusual blending wherein the meaning and the sound of the word are more important than the general blending rules. It is especially used by the younger, citybased generation.

Writing in The Daily Record, Shari Low explains that “... a recent study concluded that 67 per cent of us consider our pals to be just as important as our extended families. Now that relatives are often spread across the country or the globe, we are replacing traditional relations with friends, coining a new term for our collective chumfest"framilies"" (Shari Low, "Someone tell Paris girl pals are forever," Daily Record, October 16, 2008 $<$ http://wordspy.com/words/framily.asp> May 22, 2012).

Examples: Using the corpus, WebCorp, 62 examples were found, some of which are given below:

I hope you have some framily too.

You must turn to your framily.

We are replacing traditional relations with friends, coining a new term for our collective chumfest 'framilies',

It can be seen that this word takes the plural form just like the word 'family'. Though this word sounds very strange, Shari Low's comment proves that it has an increasing demand in British and American culture. Framily is a new social group underpinned by the principle that good friends are the family we can choose for ourselves. Framily, our closest, hand-picked friends, contrasts with our actual family: those individuals who we may or may not like, but to whom we are inextricably and permanently linked by virtue of simple biology. In this case, blood is not thicker than water. Recent research suggests that many of us spend more time with friends than we do with family, and that we consider our most special friends to be as important to us as our actual family members. Indeed for some, these friendships mature far beyond familial relationships. The word framily, therefore, fills a gap in the lexicon for those friends we hold in such high esteem that we genuinely think of them as family.

\subsection{Frienemy/Frenemy (n): ( Friend + Enemy)}

A friend who acts like an enemy; a fair-weather or untrustworthy friend is known as Frenemy (alternately 
spelled frienemy). It is a portmanteau of friend and enemy that can refer to either an enemy disguised as a friend or someone who is both a friend and a rival. The term is used to describe personal, geopolitical, and commercial relationships both among individuals, groups or institutions. It is a synonym to traitor, betrayer or double-crosser. (McDonell-Parry, Amelia (2009-08-2009 "Why do women have frenemies?")

Examples: WebCorp showed 353 examples on 62 web pages.

a) "We are frienemies since I can remember!"

b) "Why do women have frenemies?"

c) Here are a few ways to identify a frienemy.

Comment: The term refers to a toxic person who poses as a friend but consciously wishes to harm. He is a fairweather or untrustworthy friend. In other words, it is an enemy disguised as a friend or a partner, who is simultaneously a competitor and rival. The huge number of examples proves that the term has got wide acceptance.

\subsection{Netizen (n): (Internet + Citizen)}

This word, a variant of citizen, is the result of the amalgamation of Internet and citizen. Here, the word net, a [front-] clipping of Internet, and the last part of citizen, (it)izen, are combined. The word refers to a person who interacts with others on the Internet and/or is a citizen of the Internet. A person who is a frequent or a habitual user of the Internet, or a person who spends an excessive amount of time on the net, actively involved in online communities, is also called a netizen. It is an uncommon blending whereby only the last parts of both the words are used. Netizens are also commonly referred to as cybercitizens, which has the same meaning.

Examples: Using the corpus, WebCorp, I have found 90 examples, some of which are given below:

a) China and India will soon have far larger numbers of netizens than any Westerrn nation.

b) China is holding this netizen day.

c) "Maybe in some ways we are part of the netizen family because we want communication to help connect people so there is a better world".

Comment: Previously, people used personal computers or cyber cafes to surf the net at home or the office, but, these days, through tablets, iPods, and especially mobile phones, one can use the net anywhere and any time. Today, it is very easy to reach people by Skype or facebook rather than physically visiting them. They participate more in net activities and events rather than in society. Thus, the type of person hooked up to the net 24 hours a day is called a netizen.

\subsection{Netspeak (n): (Internet + Speak)}

Netspeak is the name that has been given to the long list of acronyms and smiley faces that have evolved with the internet. Netspeak assists authors in writing English texts succinctly and conveying simple emotions. The word means the words, idioms, and peculiarities of spelling and grammar that are characteristic of online documents and communication. Here the front-clipped net of Internet is attached to speak, a free lexeme which is a usually a verb [so it follows Orwell's coinage of "Newspeak" in Nineteen Eighty-Four]. It can be synonymous with talk, chat or teen talk. Internet slang, online acronyms, net trends, and most internet-related terminology can be regarded as netspeak. Linguistically, the most interesting feature of Netspeak is its morphology. Acronyms and abbreviations make up a large part of Net jargon: FAQ (Frequently Asked Question), MUD (Multi-User-Dungeon), friendly and conversationally conducive forms, such as TIA (Thanks In Advance), BRB (Be Right Back), BTW (By The Way), and IMHO (In My Humble Opinion). Examples of emoticons are: $<3=$ Love, :-(= Sad, :- $)=$ Happy.

Examples: Using the corpus, WebCorp, I have found 101 examples, some of which are given below:

"Perhaps the next great movement in English literature will somehow be fuelled by the new phenomenon of Netspeak."

Don't assume that your kids are hiding information from you by using netspeak.

I do find it strange when I'm talking to someone in person and they use netspeak.

While it does save keystrokes, netspeak can prove very hard to read.

Comment: It is a coded language or a sociolect used primarily by youngsters. Their Netspeak usually comprises slang terms, including about sex and dating, warnings that parents are in the room, and comments about people they like or dislike etc. Because of its novelty and informality, netspeak may be looked down on by certain members of society.

\subsection{Netiquette (n): (Internet + Etiquette)}

Netiquette is the culture of the internet and the ethics and rules of network communication. It is a cyber word synonymous with internet etiquette and digital manners. It can also refer to the expected standards of behavior when taking part in online discussion groups. 'A philosophy of effective internet communication that utilizes common conventions and norms as a guide for rules and standard is the definition of Netiquette, found on (http://www.networketiquette.net/). Rules of Netiquette include: be clear, don't use ALL CAPITAL LETTERS-it's equal to shouting or screaming, be brief, do not send SPAM, don't respond to 'flames' or personal attacks etc.

Examples: Using the corpus, WebCorp, 928 examples were found, some of which are given below:

They are the ten most widely followed netiquette rules on the internet.

The Core Rules of Netiquette apply to most internet communication.

For more netiquette and high-tech business etiquette tips, you can also see our upcoming book Netiquette Essentials: New Rules for Minding Your Manners. 
Comment: The internet can be considered a virtual world on this globe. It ought to have its own culture. The cyber etiquette and digital manners between users are the rules of netiquette. They are cultural norms for status updates, email messages, privacy settings, and lists. Thus the quantity of examples demonstrates its popularity.

\subsection{Netco (n): (Internet + Company)}

The word is a proper noun. It means an Internet-based company. The word is a combination of Internet and company. Here the last part of the first word and the first part of the second word are combined together.

Examples: Using the corpus, WebCorp, 48 examples were found, some of which are given below:

a) "According to stock-tracking firm IPO.com, more than a quarter of the 71 Netcos that went public in the past year are now trading under their offering price."

Comment: The example proves that Netco is a general term for Internet based companies.

\subsection{Wasband (n): (was + husband)}

The word means a person's ex-husband. This term is a clever and euphonious blend of the words 'was' and 'husband', playing on the similar sounds of "was" and "hus." The word bears a comically negative connotation. Here 'was' is a full word and a verb but being attached to the 'band' of husband made it a noun. It is an unusual blending where a full word and the last part of a word have been used. It sounds nicer than ex-husband and is also shorter and pithier.

Examples: Using the corpus, WebCorp, 89 examples were found, some of the most interesting ones of which are given below:

I'd love to go out for drinks, but I have to deal with my idiot wasband tonight.

"Hey, that's a really nice bracelet." "Thanks, it was the last birthday present I got from my wasband."

" $S$ " is my wasband. Now, I'm married to "Q". He's my "Is-band".

Comment: It is synonymous with former husband. The word reflects the modern culture which accepts the frequent changing of husbands. This may indicate the light-hearted or blasé attitude to marriage breakups these days that had not existed in former times. In example (b) Isband refers to present husband. This word does have a negative connotation like the previous word wasband.

\subsection{Yestertech (n): (Yesterday + Technology)}

The word means the technology of yesteryear. This word is normally used in a positive sense to describe older technologies that had fewer bells and whistles, and so were not as complex as the very latest technologies of today. In other words, it describes a device of mechanical or electrical methodology or technology which has been made obsolete by current standards, practices and methodologies.
A rotary dial telephone is an example of yestertech. Here the first parts of yesterday and technology (yester + tech) are combined together to coin the word.

Examples: Using the corpus, WebCorp, 105 examples were found, some of which are given below:

As a motor car, this latest Rolls-Royce is a triumph of adaptation and modern methods overlaid on a solid platform of yestertech.

Your mom likes the yestertech of the VCR because the DVD remote is difficult to use.

Fountain pens are yestertech, but they have a wonderful aura, and the same is true with safety razors.

b) Champ car is much more yestertech, though by no means low-tech.

Comment: It can be seen that yester is added to many base words to coin new words indicating the meaning earlier or before. By using this word we can elide/eliminate three or four words of a sentence. In this way, many other words, like Yestereve (yester + evening), Yestermorn (yester + morning), Yesternight (yester + night), and Yesternoon (yester + afternoon), are coined. These words made from yester may gain a place in general term dictionaries in the course of time.

\subsection{Fluffragette (n): (Fluff + Suffragette)}

The word refers to a woman with pre-feminist views. Suffragette means a woman living in countries such as Britain, Australia or the United States in the early 20th century who was a member of a group that demanded the right to vote for women and increased awareness of the matter with a series of public protests. Actually, it was checked online. The researcher does not think it is from flu + suffragette, but rather fluff + suffragette. Fluff has the two meanings of light/insubstantial and to make an error. Thus, a fluffragette is a woman unreconstructed by the feminist movement: like pre-feminist women, she tries to manipulate men by fluttering her eyelashes and giggling etc.-i.e. using her looks, feminine wiles, and sexual power By behaving like this, she does a disservice to the suffragette/real feminist movement.

Examples: Using the corpus, WebCorp, 40 examples were found, some of which are given below:

She may never be a Germaine Greer, but she can drink sloe gin, subscribe to the Financial Times and join the Fluffragettes.

Actually, what I really wanted was to become World President of the entire Fluffragette Movement.....

.....I looked down at her feet and I then realized that I had been accosted by a Fluffragette.

I'm no fluffragette, but I swear if I get one more superstitious woman-hating clergyman, I'm going to consider prescribing forcible gender reassignment surgery.

Comment: Talking about women's rights is considered here to be a disease and so the insertion of flu evidently carries a negative connotation of feminism. 


\subsection{Execubabble (n): (Executive + Babble)}

It is a type of verbal (or written) executive communication. It is characterized by an unwarranted use of (a surfeit of) 'executive' words (i.e. a mixture of jargon and clichés that may be difficult to understand clearly and may indeed be largely meaningless). Another feature of execubabble is that it never follows the tradition pattern of turn taking. There may not be any pauses between utterances.

Examples: The example in the case of this word is a bit different because instead of using a sentence containing execubabble, a sentence expressing the meaning of it may be worthy. Using the corpus, WebCorp, 21 examples were found, some of which are given below:

Question: "How is the company doing?"

Answer: "We are entering a quarter in which we expect robust growth.

Paradigms are shifting, but the team has drilled down to the heart of the challenge."

Comment: It is terminology used in the business world (perhaps analogous to hyperbole in English Literature).

\subsection{Execuspeak (n): (Executive + Speak)}

It is a type of speech characteristically used by executives. Here, the first part execu is blended with free morpheme speak. Businesspeople are faced with many challenges, such as managing their time and staff, meeting goals, motivating people, communicating in the virtual workplace etc. Productivity and performance are woven throughout these challenges. The person who meets these challenges effectively is the one who will succeed. Execuspeak is what a businessperson may adopt as part of the attempt to give credible, convincing and dynamic presentations. These days we see Execuspeak seminars and conferences and the like that teach how to project strength and enthusiasm in your speaking voice, how to choose phrases and words that will stimulate and persuade your audience, how to use microphones and lecterns as effective props, the professional way to use visual aids, and ways to control your nervousness and apprehension etc. Thus it is the language of business.

Examples: Using the corpus, WebCorp, 17 examples were found, one of which is given below:

"I went with my demands about couldn't defend myself in front of my chief's Execuspeak."

Comment: Excessive use of execuspeak may make people feel it is synonymous with 'execubabble'.

\subsection{Anecdata/Anec-data (n) :(Anecdotal + Data)}

It refers to anecdotal evidence used as data in an attempt to prove a hypothesis or to make a forecast. Anecdotal data is often adduced in spades to 'prove' the pseudo-scientific claims of products and treatments and such like. Anecdata is pseudo-data produced from anecdotes. [The term implies skepticism because the evidence is purely anecdotal rather than empirical]. Here, anec, the first part of the base word is added to the free morpheme data.

Examples: Using the corpus, WebCorp, around 65 examples were found, some of which are given below:

Jenny McCarthy uses anecdata gathered from dozens of accounts to support her pseudo-scientific treatment for childhood autism.

a) ...can you give me the anecdata on the consumer experience?

b) The viewer might believe this anecdata was real data about bonus returns.

Comment: Certainly this type of word is marginal and rarely used by general people.

\subsection{Robocall/ Robo-Call (n): (Robot + Call)}

It refers to an automated phone call that plays a recorded message. It is an automated phone call that uses both a computerized auto-dialer and a computer-delivered prerecorded message. A robocall, a telephone call from a robot, is a mass communications technique that sends a prerecorded phone message to hundreds or thousands of call recipients at once. Robocalls are often associated with political and telemarketing phone campaigns. Here robo comes from the word robot and then is attached to call, a free morpheme.

Examples: Using the corpus, WebCorp, 70 examples were found, some of which are given below:

a) Obama also recorded an automated robocall to urge Massachusetts voters to support the Democrat, and he cut a Web video with the same message.

b) Each time you get a robocall, fill in the Report.

A Robocall Form.

c) Did you get a robocall?

Comment: Different types of spelling of this word prove that morphologically the word is not established yet. However, as it is a proper name for a modern technique, and given its increasing usage in/by international politics, propaganda, business, the FBI, and high class society etc. the word may have a greater possibility to gain permanence.

\subsection{Transgenic (adj): (Transplantation + Genetical)}

The word describes an animal or plant that has been genetically altered. A transgenic animal is one that carries a foreign gene that has been deliberately inserted into its genome. The foreign gene is constructed using recombinant DNA methodology. In addition to a structural gene, the DNA usually includes other sequences to enable it to be incorporated into the DNA of the host and to be expressed correctly by the cells of the host.

It is an adjective. Here, the first part trans comes from transplantation, and the last part genic comes from genetical. It is an unusual blending. Before the coinage of this word, the phrases 'genetically transplanted' or 'genetical transplantation' were used. Thus, this is an economical usage in the scientific or technical milieus.

Examples: Using the corpus, WebCorp, 499 examples were found, some of which are given below: 
There has been less concern about transgenic livestock, in part because the reproduction of animals, unlike that of field crops, can be tightly controlled.

Transgenic animals are used as experimental models to perform phenotypic and for testing in biomedical research.

Transgenic mice are often used to study cellular and tissue-specific responses to disease.

Comment: The large number of examples proves that this word has gained acceptance.

\subsection{Textpectation (n): (Text + Expectation)}

Textpectation is the feeling of anticipation one gets waiting for a response to a text message.

Examples: Using the corpus, WebCorp, 58 examples were found, some of which are given below:

a) "I looked at my phone just as I got a text; I think it was the textpectation I was feeling in the air."

b) I just texted her for a date - but now the textpectation is killing me.

c) "Hey did you just send me a text?" "No why?"“Oh...just had a textpectation."

d) I went through textpectation very often; it makes me feel bad about myself. Is there any cure for it?

Comment: The word conveys a modern feeling and dispiriting preoccupation prevalent in the mobile phone society.

\subsection{Vegangelical (n): (Vegan and Evangelical)}

The word refers to an extremely ardent vegan (vegetarian) who is eager to make other people believe in and convert to veganism, just as evangelicals zealously try to convert people to their religion.

Example: Using the corpus, WebCorp, 20 examples were found, one of which is given below:

Isa Chandra Moskowitz and Terry Hope Romero are vegangelicals with a sense of humor, a sense of proportion and a sense of adventure.

Comment: Vegans are people who love animals very much and/or who hate the slaughtering of animals for humans to eat or get leather and such like (some vegans will not even drink milk or eat eggs). When vegans proselytize to non-vegans, trying to convert them to the same radical way of thinking and lifestyle with a zeal that may be considered excessive or even extreme, the term vegangelical might be applied.

\subsection{Thumbo (n): (Thumb + Typo)}

The word, thumbo, refers to an error made while using the thumbs to type, particularly on a mobile device keypad. The word is mainly used by youngsters.

Example: Using the corpus, WebCorp, around 21 examples were found, one of which is given below:

How do you get rid of "thumbos", those cellphone message typos? Practice some handy tips.

Comment: The word is probably created from words such as; Typo is an old word which means a mistake made while typing and speako, used to indicate mistakes made while dictating text. It may also be related to the idiom for clumsiness, 'to be all fingers and thumb'.

\subsection{Flirtationship (n): (Flirt + Relationship)}

The word refers to a situation in which someone regularly flirts with an acquaintance or friend, but it never goes any farther than that. It is more than a friendship, less than a relationship. Lots of flirting is going on, and someone may or may not want it to go farther. In this blending, the first word (flirt) is fully taken and then the last part (ationship) of the second word is attached to it.

Examples: Using the corpus, WebCorp, around 72 examples were found, some of which are given below

a) They aren't in any sort of relationship, merely a flirtationship.

Bob has only one girlfriend, but starts a flirtationship with almost every girl he meets.

My flirtationship with Kody went to a whole new level when we went on a date last night.

Comment: Flirtationship is a modern type of relationship in today's society. It indicates a society in which monogamous relationships are perhaps not very valued. People know each other, they flirt, make fun of each other etc., but they are not ready to take any responsibility for the relationship. Such relationships basically occur in offices where forming real permanent romantic/monogamous relationships may be awkward but flirtationships can be maintained to make office life a little more stimulating and enjoyable. This feature of modern culture may be taken by some to reflect a degrading and hampering of the conjugal lives left back at home while the parties participate in their flirtationships while out at work.

Findings:

The above investigation shows that all the new blended words have been created in ways that comply with some new blending rules (and patterns). The subcategories of these new blending rules (or patterns) are shown below:

- One or more letters of one word is/are inserted into another, such as framily.

- The last parts of both words are combined, such as netizen.

- The second part of the first word and the second word (in its entirety) are combined together, such as netspeak.

- The last part of the first word and the first part of the second word are combined together, such as netco.

- The first parts of both words are combined together, such as yestertech.

- The first word and the second part of the second word are combined together, such as wasband, thumbo etc.

- The first part of the first word and the last part of the second word are combined together, such as yesteryear, execubabble, anecdata. 
Table 1. An overview of the new Blend

\begin{tabular}{|c|c|c|c|c|}
\hline No. & New words & Division of the new word & Blended $1^{\text {st }}$ part & Blended $2^{\text {nd }}$ part \\
\hline 1 & Framily & family + friend & Family & (f)r(iend) \\
\hline 2 & Frienemy/Frenemy & Friend + enemy & Fri(end) & Enemy \\
\hline 3 & Netizen & Internet + citizen & (Inter)net & (cit)izen \\
\hline 4 & Netspeak & Internet + speak & (Inter)net & Speak \\
\hline 5 & Netiquette & Internet + etiquette & (Inter)net & (et)iquette \\
\hline 6 & Netco & Internet + company & (Inter)net & co(mpany) \\
\hline 7 & Wasband & Was + husband & was & (hus)band \\
\hline 8 & Yestertech & yesterday + technology & Yester(day) & Tech(nology) \\
\hline 9 & Fluffragette & influenza + suffragette & (in)flu(enza) & (su)ffragette \\
\hline 10 & Execubabble & executive + babble & execu(tive) & Babble \\
\hline 11 & Execuspeak & executive + speak & execu(tive) & Speak \\
\hline 12 & Anecdata & Anecdotal + data & Anec(dotal ) & data \\
\hline 13 & Robocall & robot + call & robo(t) & Call \\
\hline 14 & Transgenic & transplantation + genetical & Trans(plantation) & Gen(et)ic(al) \\
\hline 15 & Textpectation & text + expectation & text & (ex)pectation \\
\hline 16 & Vegangelical & vegan +evangelical & vegan & (Evan)gelical \\
\hline 17 & Thumbo & thumb + typo & thumb & (typ)o \\
\hline 18 & Flirtationship & (flirt+ relationship) & flirt & (rel)ationship \\
\hline
\end{tabular}

\section{Justification}

Traditional linguists believe that neologisms should be excluded from the study of linguistics. However, David W Maurer (1980) and Adrienne Lehrer (1996) have given some justifications for why new words should be studied. Rita Brdar-Szabó \& Mario Brdar (2008: 172,173) contend that, as "conceptual blending is claimed to be one of the central cognitive processes, omnipresent in our daily lives, from online reasoning to arts to communication, and that it underlies a whole range of linguistic phenomena, it comes as somewhat of a surprise that lexical blending should be so marginal".

Brdar-Szabó and Brdar (2008) make a compelling case for the importance of studying blended neologisms in linguistics, one that helps dispel objections. If we were to think that these words (discussed above) are marginal, it would be unfortunate, because these creative neologisms tell us a great deal about important aspects of word formation. The study of creative neologism can help us understand the development of semantic change and polysemy. These words clearly show that the blending process follows more diverse patterns than his hitherto been recognized now-a-days. Moreover, in semantics and pragmatics, creative neologisms have been recognized as legitimate objects of study. It can also increase the number of word formation processes. There is no reason to be wed forever to the old explanations of word formation processes when they no longer universally apply. One reason that might be given for not taking neologisms seriously is that they are ephemeral; they do not stay in the language. This claim is not completely true. Although some may die out, others become part of the language, whether they be used widely or narrowly. Either way, these words are found in complete sentences in WebCorp. The widely-used words speak for themselves, and the narrowly-used ones are used in specific cultures so the general public may not know about them even though they are definitely irrefutably used in their (those) subcultures.

Another objection is that neologisms are often found only in specific fields, such as advertising, journalism, and cartoons. This objection is puzzling (and paradoxical) because so much that is studied in linguistics belongs to special registers: for example, the kinds of vocabulary and sentences used in academic linguistic articles on formal syntax exist only in the genre of linguistics writing.

Related to genre is the objection that many neologisms are humorous, i.e. not serious. The researcher suspects that this is not true; it is simply that we notice the humorous, clever, and witty neologisms more. Regardless of whether or not it is true, though, there is still no good reason to exclude humorous or cute words from scientific study. As 
well as including clever and humorous new words like wasband and execubabble, the researcher have also talked about technical and serious words such as transgenic, robocall, and yesterweek to try to show a broader spectrum of neologisms than merely the humorous ones.

\section{Conclusion}

Language has become an important issue all over the world today. It is a well known historical fact that all languages are constantly in a state of change. Changes can occur in grammar or vocabulary. However, English, unlike other languages, is recognized as the world's international language. Every day, millions of people in the world communicate in English, so change or novelty in English becomes more notable than that in any other language. In my paper, some new words that have been created from socalled atypical blending processes are shown. The use of such blending has become so frequent that these new processes should be recognized and accepted as new rules. Generally, the established rule of blending is that the first part of one word is added to the last part of another word, and the new word formed conveys the combined meaning of the two words. However, this is patently no longer the only way to blend words into a neologism. Therefore, if the new rules were added to the old one, the study of neologisms would become a little easier for learners. Besides, vocabulary is the heart of a language, and the ever-expanding realms of technology and other discoveries demand new words. Lehrer's creation of the word blendalicious (blend + delicious) proves the increasing demand of blends (2007: 115). Coining an exact word for an exact thing or situation helps to shorten the expression and often increase its intelligibility; our neo-blends can enrich beautifully the lexical stock of English language.

\section{References}

[1] Algeo, J. (1977). Blends, a structural and systemic view. American Speech 52, 47-64.

[2] Algeo, J. (1991). Fifty Years among the New Words: A Dictionary of Neologisms, Cambridge: Cambridge University Press.

[3] Bauer, L. (1983). English Word-Formation. Cambridge: Cambridge University Press.

[4] Brdar-Szabó, R., \& Brdar, M. (2008). On the marginality of lexical blending. Jezikoslovlje, 9(1-2), 171-194.

[5] Cannon, Garland (1986). Blends in English word formation. Linguistics 24, 725-753.

[6] Gries, S. (2004). Shouldn't it be breakfunch? A quantitative analysis of blend structure in English. Linguistics 42(3), 639-667.

[7] Kemmer, Suzanne (2003). Schemas and lexical blends. Motivation in Language: From Case Grammar to Cognitive Linguistics. A Festschrift for Gunter Radden. Thomas Berg et al. (eds.), 69-97. Amsterdam and Philadelphia: Benjamin.

[8] Lehrer, A. (2007). Blendalicious. From Lexical Creativity, Texts and Contexts. Judith Munat (ed.), 115-133. Amsterdam and Philadelphia: Benjamin.

[9] Lehrer, A. (1996). Why neologisms are important to study? Lexicology 2(1). 63-73.

[10] Maurer, D. W. \& High, E. C. (1980). New Words -Where Do They Come From and Where Do They Go? American Speech, 55(3), 184-194.

[11] McFedries, P. (2004). Word spy: The word lover's guide to modern culture. New York: Broadway Books. 